GSA DATA REPOSITORY 2010022

Beer et al.

\title{
Station Locations and Number of Specimens
}

Table DR1 displays the station locations and number of specimens employed in each aliquot. A mean of 24 specimens were employed in each aliquot, with a minimum of 10 and maximum of 73 .

\section{Normalisation procedures}

Test diameter is conventionally used as a gauge of size (because it is easily measured) but we instead employ test area because it should provide a better basis from which to estimate test volume, the desired variable when determining size-normalized weight. We find that test area and mean diameter are highly correlated $\left(\mathrm{r}^{2}=0.98\right)$, hence sizenormalisation using either measure does not alter the SNW trends observed or affect our findings.

\section{The Potential Influence of Gametogenesis and Ontogeny}

The micro-morphology of a planktic foraminiferal test changes during ontogeny (Brummer et al., 1987; Hemleben et al., 1989). An important morphological change is the precipitation of a smooth veneer of $\mathrm{CaCO}_{3}$, known as 'gametogenic calcite' within a rhizopodal envelope which surrounds the test (Bé, 1980; Hamilton et al., 2008). The addition of gametogenic calcite is a highly variable process, both within and between species. For example, G. sacculifer precipitates gametogenic calcite which can increase the mass of the test by nearly $30 \%$ (Bé, 1980), whereas G. ruber (used in this study), 
precipitates no gametogenic calcite (Hamilton et al., 2008). Consequently, the SNW of G. ruber specimens collected from surface waters can be directly compared to tests sampled from surface sediments, without the added complication of gametogenic calcite crusts. However, ontogeny may influence SNW- $\left[\mathrm{CO}_{3}{ }^{2-}\right]$ calibrations and, in particular, comparisons of calibrations derived using different size fractions. To test this possibility, specimens of G. ruber from various size fractions collected from surface waters were weighed (Fig DR1). The SNW-[CO $\left.{ }_{3}^{2-}\right]$ gradients are virtually indistiguishable between size fractions (Table DR2), as has been shown in culture (Bijma et al., 2002), which suggests that ontogeny does not influence such calibrations.

The species G. bulloides, also used in this investigation, is not well-studied with respect to gametogenic calcification. Some researchers, using seafloor sediment samples, report that the spine holes of virtually all G. bulloides specimens larger than $150 \mu \mathrm{m}$ are covered by gametogenic calcite, albeit much less significant than that of G. sacculifer (Schiebel et al. 1997; R. Schiebel, unpublished data). Others suggest that G. bulloides adds no gametogenic calcite (Hamilton et al., 2008). This discrepancy may be traceable in part to the fact that gametogenic calcification does not readily occur in culture and in part to difficulties associated with the unequivocal visual identification of minor crusts. Regardless, by employing specimens collected from a narrow size fraction $(250-250 \mu \mathrm{m})$, we ensure that all specimens used come from a similar ontogenetic stage and we therefore minimize the influence of ontogeny and gametogenesis in our dataset. 


\section{Environmental Data: establishing $\left[\mathrm{CO}_{3}{ }^{2-}\right]$}

Environmental data, measured synchronously with MCN sampling, were sourced from either the respective cruise reports directly or published online archives

(www.pangaea.de). Total alkalinity was calculated using sea surface temperature (SST) and salinity (SSS) data input into the regionally specific equations of Lee et al. (2006). Carbonate ion concentration was derived using either DIC or $\mathrm{fCO}_{2}$ measurements, depending on availability, and calculated using the program of Lewis and Wallace (1998) and equilibrium constants of Roy et al. (1993). Use of the alternative equilibrium constants of Mehrbach et al. (1973) refit by Dickson and Millero (1987) results in different absolute values for $\left[\mathrm{CO}_{3}{ }^{2-}\right]$ and different correlation coefficients between $\mathrm{SNW}$ and $\left[\mathrm{CO}_{3}{ }^{2-}\right]$, but do not significantly change our main findings.

\section{Size-normalized weight versus Salinity and Temperature}

In an upwelling system, such as the one studied here, multiple environmental variables, such as temperature, salinity and water carbon chemistry tend to co-vary. Upwelled waters are generally cooler, fresher and have a lower $\left[\mathrm{CO}_{3}{ }^{2-}\right]$ than their oligotrophic counterparts. Hence, a correlation observed between SNW and any individual environmental variable (e.g. $\left[\mathrm{CO}_{3}{ }^{2-}\right]$ ) does not necessarily imply causation. In Figure DR2 we plot SNW of G. bulloides and G. ruber specimens not only against $\left[\mathrm{CO}_{3}{ }^{2-}\right]$ (as in Fig. 2), but also temperature, and salinity. Generally, the SNW of G. bulloides is greatest and the SNW of G. ruber smallest in cold, fresh, low-[ $\left.\mathrm{CO}_{3}{ }^{2-}\right]$ (i.e. upwelled) waters. 


\section{Figures}

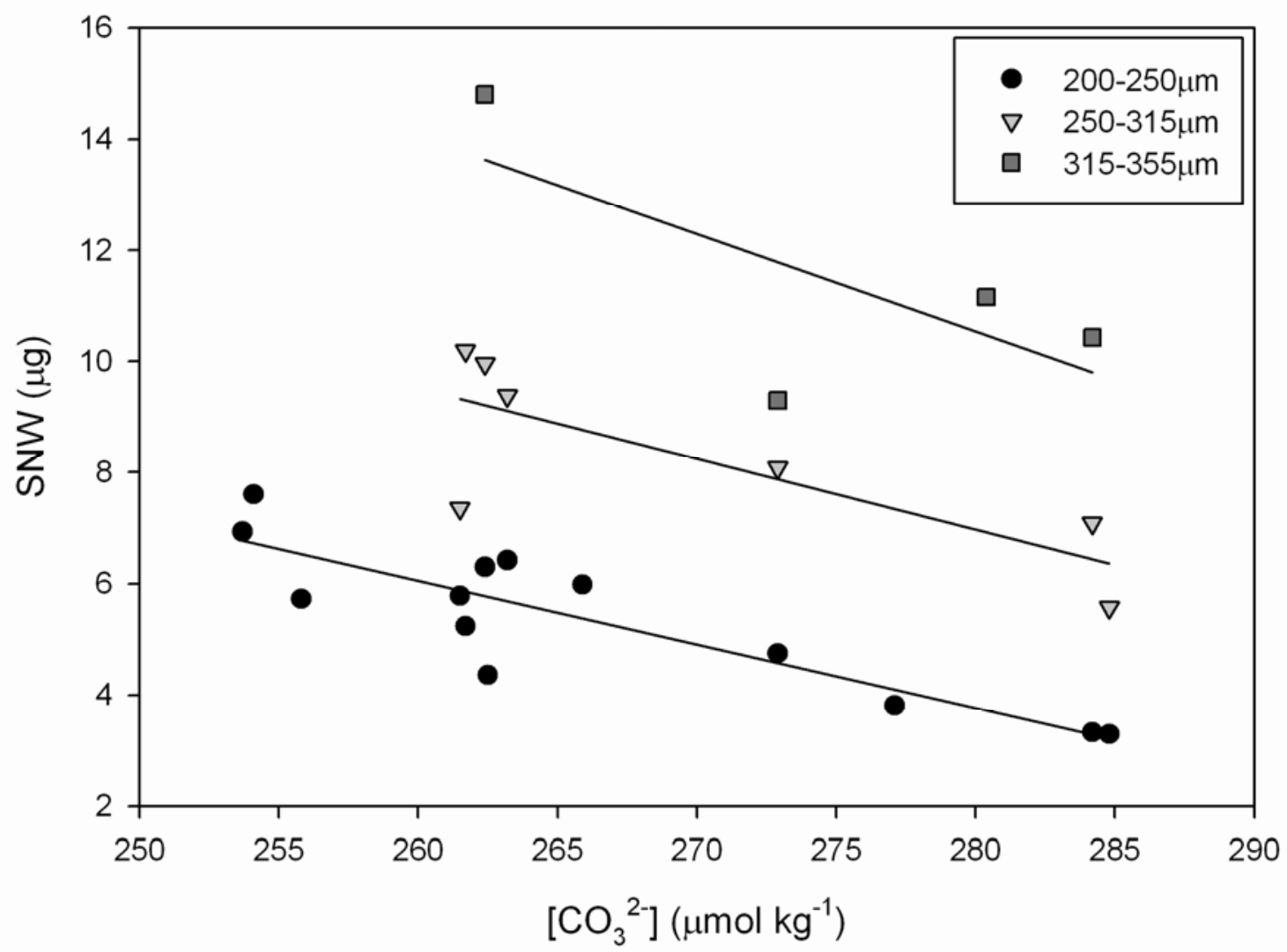

Figure DR1. Size-normalized weight (SNW) of G. ruber specimens of different size fractions collected in waters $<60 \mathrm{~m}$ against surface water $\left[\mathrm{CO}_{3}{ }^{2-}\right]$. 

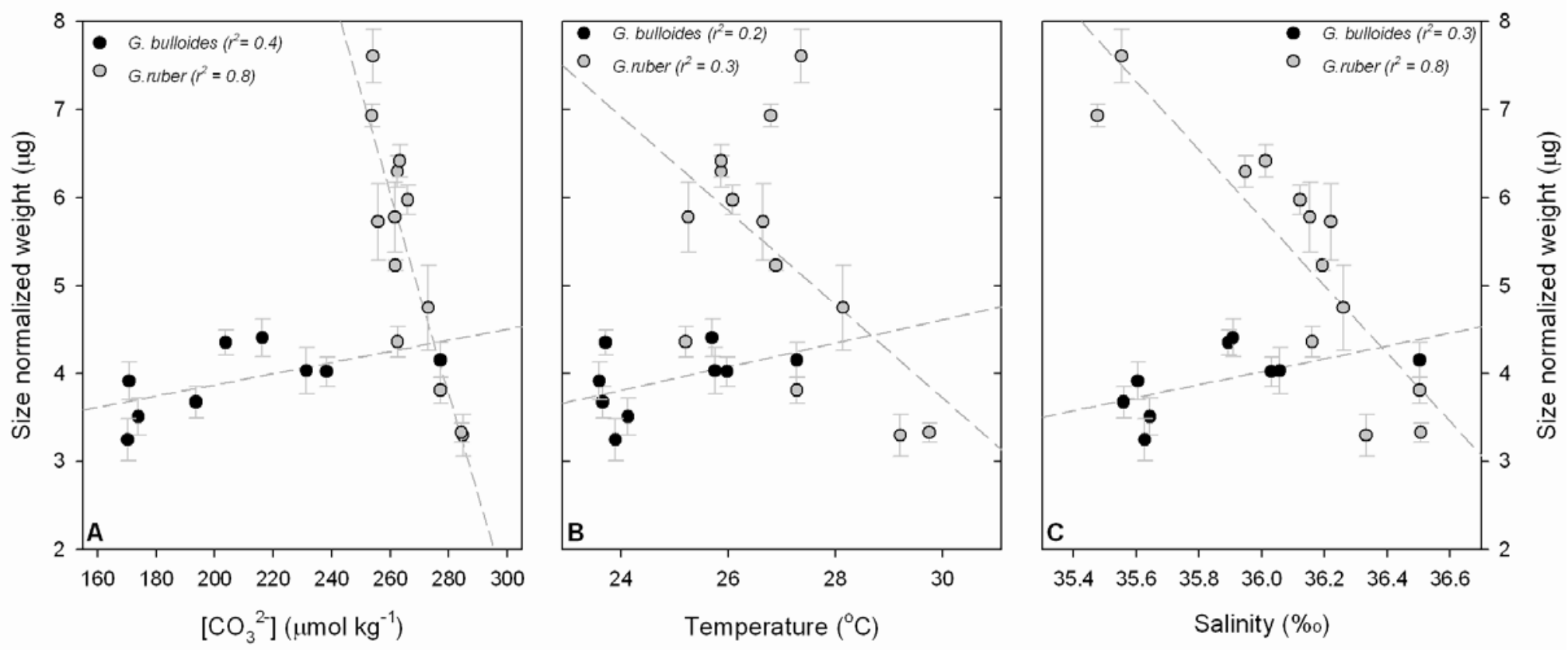

Figure DR2. Size-normalized weight of G. bulloides (black circles) and G. ruber (gray circles) versus $\left[\mathrm{CO}_{3}{ }^{2-}\right]$ (a), temperature (b), and salinity (c) of surface $(<10 \mathrm{~m})$ waters. Error bars are based on the reciprocal of the number of specimens weighed per aliquot multiplied by the mean specimen weight. 

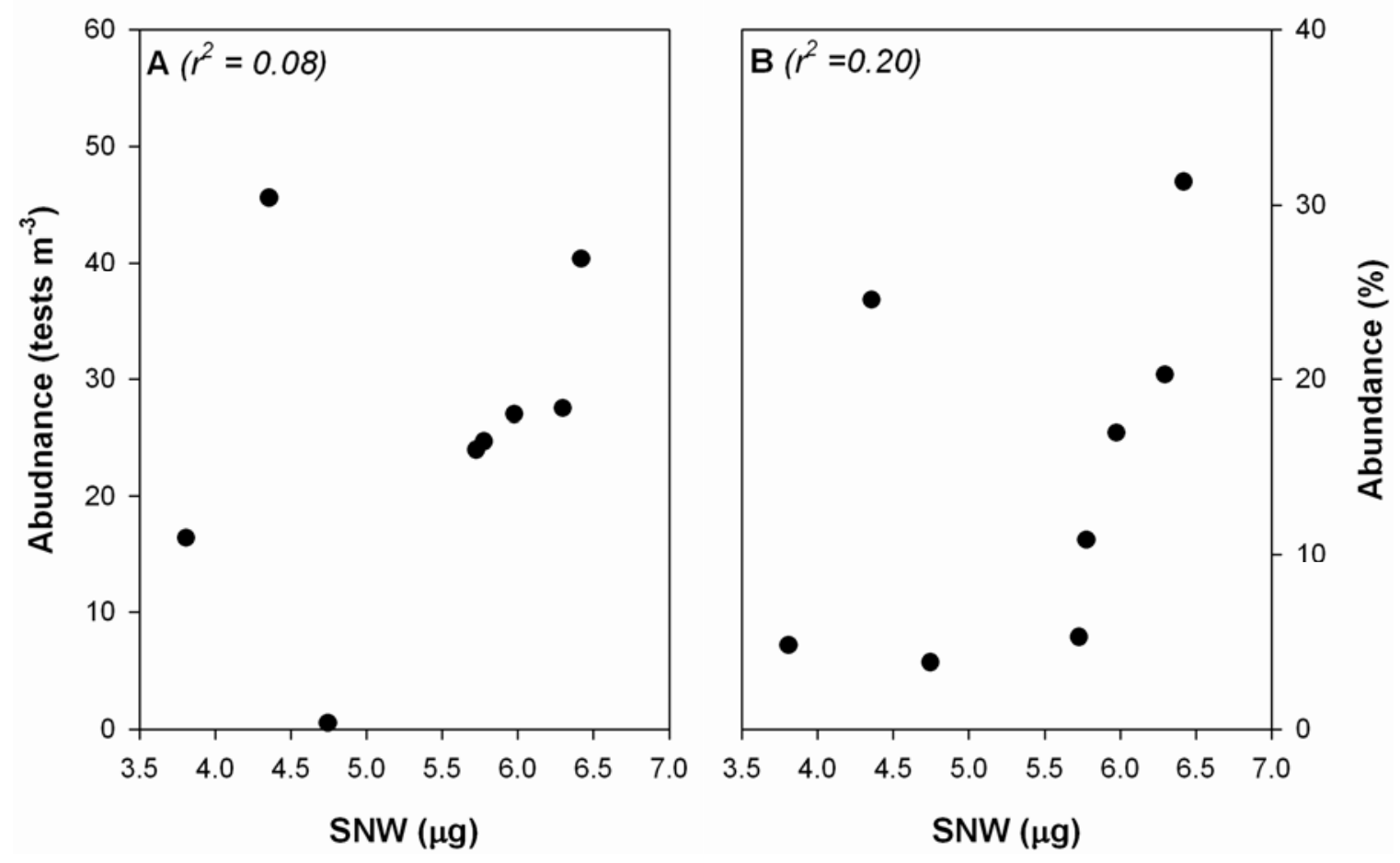

Figure DR3. SNW of G. ruber versus absolute (A) and relative (B) abundance of tests $(>100 \mu \mathrm{m})$ collected from the upper $100 \mathrm{~m}$ of the water column. Correlations are not observed in either case. 
Table DR1. Cruise number $(\mathrm{M}=$ FS Meteor, $\mathrm{SO}=$ FS Sonne $)$, station identification, locations and number of tests per aliquot employed to establish SNW.

\begin{tabular}{cccccc}
\hline Cruise & Station & Lat $\left({ }^{\circ} \mathbf{N}\right)$ & Lon $\left({ }^{\circ} \mathrm{E}\right)$ & $\begin{array}{c}\text { G. ruber } \\
\mathbf{n}\end{array}$ & $\begin{array}{c}\text { G. bulloides } \\
\mathbf{n}\end{array}$ \\
\hline M31-3 & 106 & 13.49 & 50.30 & 33 & \\
M31-3 & 107 & 14.60 & 52.92 & 23 & \\
M31-3 & 108 & 14.99 & 54.39 & 30 & \\
M31-3 & 113 & 16.54 & 55.33 & 52 & \\
M31-3 & 114 & 14.54 & 51.76 & 23 & \\
M31-3 & 115 & 13.31 & 48.78 & 73 & \\
M31-3 & $110-4$ & 16.22 & 60.27 & 19 & \\
M31-3 & $111-1$ & 16.17 & 59.76 & 11 & \\
M32-5 & 414 & 14.45 & 65.02 & & 23 \\
M32-5 & 423 & 16.03 & 62.02 & & 16 \\
M32-5 & 430 & 17.10 & 60.02 & 13 & \\
M32-5 & 443 & 18.12 & 58.05 & & 23 \\
M32-5 & 446 & 17.68 & 58.88 & & \\
M32-5 & 462 & 16.00 & 62.00 & & \\
SO119 & 3 & 19.95 & 65.83 & 12 & \\
SO119 & 7 & 16.20 & 60.31 & 26 & \\
SO119 & 28 & 17.31 & 58.39 & 19 & \\
SO119 & 36 & 19.04 & 58.82 & 10 & \\
SO120 & 20 & 17.97 & 57.20 & & 23 \\
SO120 & 38 & 17.74 & 57.61 & & 19 \\
SO120 & 41 & 17.45 & 57.74 & & \\
SO120 & 43 & 17.26 & 57.95 & & \\
\hline
\end{tabular}

Table DR2. The percentage change in sizenormalized weight ( $\mathrm{SNW}$ ) given a $\left[\mathrm{CO}_{3}{ }^{2-}\right]$ change from 200 to $300 \mu \mathrm{mol} \mathrm{kg}^{-1}$ for various size fractions of $G$. ruber.

\begin{tabular}{cc}
\hline $\begin{array}{c}\text { Size Fraction } \\
(\boldsymbol{\mu m})\end{array}$ & $\begin{array}{c}\% \Delta \mathrm{SNW} \\
\text { given }\left[\mathrm{CO}_{3}{ }^{2}\right]_{\mathbf{2 0 0 - 3 0 0}}\end{array}$ \\
\hline $200-250$ & -88.6 \\
$250-315$ & -74.2 \\
$315-355$ & -71.5 \\
\hline
\end{tabular}

\section{References}

Bé, A.W.H., 1980, Gametogenic calcification in a spinose planktonic foraminifera, Globigerinoides sacculifer (Brady): Marine Micropaleontology, v. 5, p. 283-310. 
Bijma, J., Honisch, B., and Zeebe, R.E., 2002, Impact of the ocean carbonate chemistry on living foraminiferal shell weight: Comment on "Carbonate ion concentration in glacial-age deep waters of the Caribbean Sea" by W. S. Broecker and E. Clark: Geochemistry Geophysics Geosystems, v. 3.

Brummer, G.-J.A., Hemleben, C., and Spindler, M., 1987, Ontogeny of extant spinose planktonic foraminifera (Globigerinidae): A concept exemplified by Globigerinoides sacculifer (Brady) and G. ruber (d'Orbigny): Marine Micropaleontology, v. 12, p. 357-381.

Dickson, A.G., and Millero, F.J., 1987, A Comparison of the Equilibrium-Constants for the Dissociation of Carbonic-Acid in Seawater Media: Deep-Sea Research Part aOceanographic Research Papers, v. 34, p. 1733-1743.

Hamilton, C.P., Spero, H.J., Bijma, J. and Lea, D.W., 2008, Geochemical investigation of gametogenic calcite addition in the planktonic foraminifera Orbulina universa: Marine Micropaleontology, v. 68, p. 256-267

Hemleben, C., Spindler, M., and Anderson, O.R., 1989, Modern Planktonic Foraminifera, Springer Verlag.

Lee, K., Tong, L.T., Millero, F.J., Sabine, C.L., Dickson, A.G., Goyet, C., Park, G.-H., Wanninkhof, R., Feely, R.A., and Key, R.M., 2006, Global relationships of total alkalinity with salnity and temperature in surface waters of the world's oceans: Geophysical Research Letters, v. 33.

Lewis, E., and Wallace, D.W.R., 1998, Program Developed for $\mathrm{CO}_{2}$ System Calculations. ORNL/CDIAC-105. Carbon Dioxide Information Analysis Center, Oak Ridge National Laboratory US Depeartment of Energy, Oak Ridge, Tennessee. 
Mehrbach, C., Culberso.Ch, Hawley, J.E., and Pytkowic.Rm, 1973, Measurement of Apparent Dissociation-Constants of Carbonic-Acid in Seawater at AtmosphericPressure: Limnology and Oceanography, v. 18, p. 897-907.

Roy, R.N., Roy, L.N., Vogel, K.M., Porter-Moore, C., Pearson, T., Good, C.E., Millero, F., and Campbell, D.M., 1993, The dissociation constants of carbonic acid in seawater at salinities 5 to 45 and temperature $0-45^{\circ} \mathrm{C}$ : Marine Chemistry, v. 44 , p. 249-267.

Schiebel, R., Bijma, J., and Hemleben, C., 1997, Population dynamics of the planktic foraminifer Globigerina bulloides from the eastern North Atlantic: Deep-Sea Research Part I-Oceanographic Research Papers, v. 44, p. 1701-1713. 